\title{
Pyruvate Kinase and Phosphofructokinase Isozymes in Childhood Cancers
}

\author{
DOMINIQUE COTTREAU, MARIE-FRANÇOISE ROUSSEAU-MERCK, CHRISTIAN NEZELOF, AND \\ AXEL KAHN ${ }^{(30)}$ \\ INSERM U 129, Institut de Pathologie Moléculaire, CHU Cochin, Paris, France [D.C. A.K.] and INSERM U 77, \\ Hôpital des Enfants Malades, Paris, France [M.-F.R.-M. C.N.]
}

\begin{abstract}
Summary
Pyruvate kinase and phosphofructokinase isozymic expression have been investigated in 62 childhood cancers by electrofocusing and immunoneutralization. Isozymic expression was roughly intermediate between that of the corresponding normal adult and fetal tissue. There were unique features distinguishing malignant from both adult and fetal tissues. In addition, phosphofructokinase and pyruvate kinase appeared to be excellent markers for nervous tissue and skeletal muscle differentiation. In neuroblastomas there was a close relationship between the differentiation level of tumors and their isozyme composition. The same phenomenon was observed in rhabdomyosarcomas and teratomas.
\end{abstract}

\section{Speculation}

Multiple isozymic markers could be used as a tool to detect some types of tumoral differentiation, the degree of this differentiation and, in some cases, degree of malignancy. In addition, the fact that the malignant tissue isozymic patterns studied never appear to be exactly similar to their normal fetal counterpart suggests that malignancy is associated with a special pattern of differentiation rather than to indifferentiation or de-differentiation alone.

Pyruvate kinase (ATP: pyruvate phosphotransferase, EC 2.7.1.40) and phosphofructokinase (ATP: D-fructose 6 phosphate 1-phosphotransferase, EC 2.7.1.11) occur in multiple isozymic forms in mammalian tissues (c.f. ref. 8). The basic pyruvate kinase isozymes (i.e., composed of a single type of subunit) are $\mathrm{L}$ (major form in liver), $\mathbf{R}$ (major form in red cells), $\mathbf{M}_{2}$ or $\mathrm{K}$ (major form in kidney), and $M_{1}$ or $M$ (major form in adult skeletal muscle and adult brain) (8). We have shown that $L$ and $R$ pyruvate kinases are encoded by the same gene $(12,18)$. Whether $M$ and $K$ subunits, which are immunologically indistinguishable, are encoded or not by separate genes is still in dispute $(6,7,17,21)$. For phosphofructokinase, we and others have shown that it is encoded by three separate genes, the products of which are subunits $M$ (predominant in the muscle), $L$ (predominant in the liver), and $F$ (predominant in fibroblasts and abundant in platelets) $(2,11,13,15,27)$. We have previously studied pyruvate kinase and phosphofructokinase isozymes in human adults or fetuses $(10,17)$. In this paper, we compare isozymic expression of these enzymes in various types of childhood cancers to that of the corresponding normal, fetal or adult tissues. The combination of pyruvate kinase and phosphofructokinase isozyme determination permits assessment of type and degree of differentiation of some malignant childhood tumors.

\section{MATERIALS AND METHODS}

Patients. Tumor samples studied were obtained from surgical biopsies or exereses and stored frozen at $-70^{\circ} \mathrm{C}$ until use. The pathologic diagnoses were: nephroblastoma (28 patients), neuro- blastoma (13 patients), seminoma (6 patients), teratoma ( 5 patients), embryonic sarcoma (5 patients), rhabdomyosarcoma (3 patients) and Ewing's tumor ( 1 patient). The level of differentiation of neuroblastomas was highly variable from one observation to another. Some of them, relatively well differentiated, were classified as ganglioneuromas and ganglioneuroblastomas whereas others, undifferentiated, were considered as true neuroblastomas.

Biochemical methods. Tissue extraction and immunoneutralization of phosphofructokinase by specific anti $\mathrm{M}$, anti $\mathrm{L}$ and anti $F$ antisera were performed as previously described $(10,11,13,19)$. Pyruvate kinase isozymes were resolved by polyacrylamide slab gel electrophoresis (17), and stained by tetrazolium salt-linked reaction with inhibition of adenylate kinase reaction by excess AMP (1). Specificity of the staining was checked by omitting phosphoenolpyruvate from some staining mixtures.

Control tissues came from 3- to 4-month-old fetuses (10, 17).

\section{RESULTS}

Isoelectric focusing is a very resolutive technique that can reveal as many as 10 discrete pyruvate kinase bands (Fig. 1). Some of these bands probably correspond to the various tetrameric combinations of $\mathrm{K}$ and $\mathrm{M}$ subunits while others probably reflect microheterogeneity. Inasmuch as it is not feasible to determine with certainty the subunit composition of each active band, they will be numbered from 1 (most cathodic form corresponding to $\mathrm{M}_{4}$ isozyme) to 10 (most anodic form). The classical $\mathrm{K}_{4}$ isozyme present in human fibroblasts migrates as band 8 (Fig. 1). We verified, using antihuman L-type pyruvate kinase antiserum, that the anodic forms did not correspond to hybrids including $L$ subunits.

Nephroblastomas. Practically all the nephroblastomas studied exhibited very similar isozymic patterns with $\mathrm{K}_{4}$ as the predominant pyruvate kinase form and synthesis of all three types of phosphofructokinase subunits. These patterns are not profoundly different from those observed in either adult or fetal kidney (Table 1). Pyruvate kinase isozymes are the same in nephroblastomas and fetal kidney whereas the major isozyme observed in the adult organ is slightly more cathodic. The three types of phosphofructokinase in nephroblastomas seem to be expressed in approximatively equivalent amounts whereas in adult kidney the predominant form is F and in fetal kidney, L. In three tumors, however, phosphofructokinase expression was clearly different from that reported above, M-type being the predominant form. In one of these tumors, histologic examination detected the presence of skeletal muscle differentiation.

Neuroblastomas (Table 2). All samples of childhood neuroblastomas were characterized by the presence of the cathodic (M) form of pyruvate kinase and of F-type phosphofructokinase as the major phosphofructokinase subunit; these features are characteristic of adult differentiated brain tissue. Some marked differences. however, exist between the various tumors according to their level of differentiation: anodic pyruvate kinase isozymes ( $\mathrm{K}$ and $\mathrm{K}-\mathrm{M}$ 


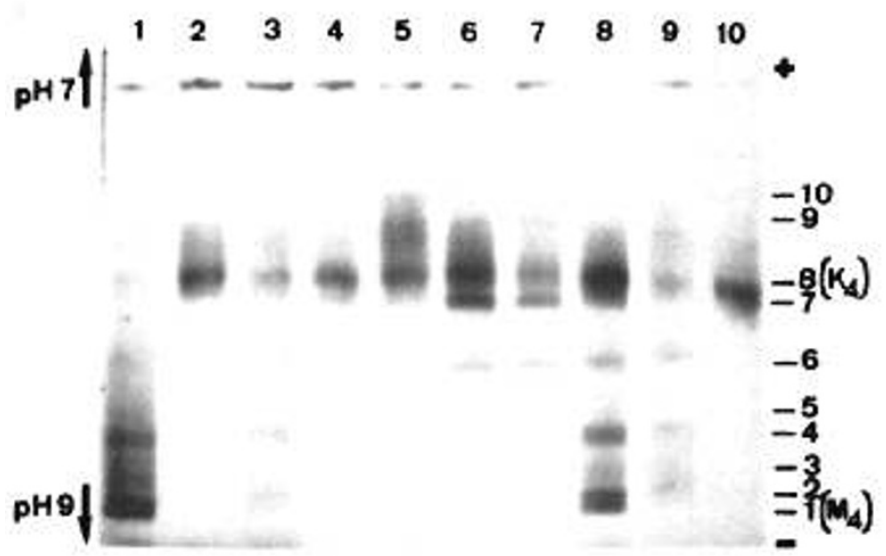

Fig. 1. Pyruvate kinase isoelectrofocusing analysis. Slab gel was $3.75 \%$ $(\mathrm{w} / \mathrm{v})$ acrylamide and contained $0.6 \%(\mathrm{w} / \mathrm{v})$ ampholine 5.8 and $0.8 \%(\mathrm{w} /$ v) ampholines 7-9. Samples (about $20 \mathrm{mIU}$ each) were applied (17) after a prerun of $1 \mathrm{~h}$ and focalisation ran for $4 \mathrm{~h}$ at $2^{\circ} \mathrm{C}$, with a final voltage of 700 volts (17). Positive staining as in (1), with addition of $12 \mathrm{mM} \cdot \mathrm{AMP}$ in order to inhibit adenylate kinase activity. 1 , fetal muscle; 2 , fibroblast; 3 , sympathoblastoma: 4, nephroblastoma: 5, teratoma; 6 , rhabdomyosarcoma; 7, nephroblastoma; 8 , well differentiated rhabdomyosarcoma; 9, neuroblastoma; and 10, nephroblastoma. hybrids) were observed in all the poorly differentiated tissues: except one (neuroblastoma 5, Table 1) but not in any of the welldifferentiated tumors (i.e., ganglioneuroblastomas and ganglioneuromas). L-type phosphofructokinase, abundant in fetal brain. was more abundant in undifferentiated tumors (mean residual activity after immunoneutralization by anti L-type antiserum: $37 \%$ ) than in ganglioneuroblastomas (57\%) and ganglioneuromas (70\%).

Miscellaneous (Table 3). Seminomas, undifferentiated teratomas and embryonic sarcomas gave an "undifferentiated cell" isozymic pattern characterized by indiscriminate synthesis of the three types: of phosphofructokinase isozymes ( $\mathrm{L}$ always being the predominant form) and the presence of anodic pyruvate kinase forms ( $\mathrm{K}$ isozyme). In one observation of a teratoma that contained nervous structures, we found abundant muscle-type phosphofructokinase and some cathodic (M) pyruvate kinase isozymes. Phosphofructokinase isozymic composition of three rhabdomyosarcomas was different in each case and did not seem to be specific for a special type of differentiation. In contrast, both tumors with marked skeletal muscle differentiation synthesized cathodic pyruvate kinase isozymes. Most surprisingly, a tumor considered by the pathologists as an "Ewing's tumor" was found to be very similar to neuroblastomas, namely with synthesis of F-type phosphofructokinase as the major form and of cathodic pyruvate kinase isozymes.

Table 1. Phosphofructokinase and pyruvate kinase isozyme composition of nephroblastomas

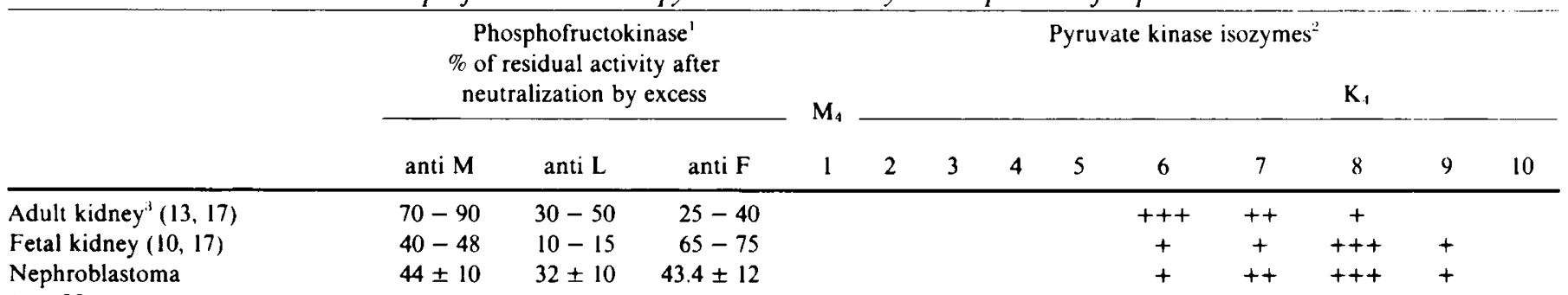

$(n=28)$

'The results of maximal phosphofructokinase immunoneutralization in nephroblastomas are given \pm I S.D.

${ }^{2}$ Relative intensity of pyruvate kinase active bands resolved by electrofocusing is semiquantitatively evaluated; band 1 corresponds to classical $M_{4}$ isozyme and band 8 to $K_{4}$ isozyme.

${ }^{3}$ The data concerning adult and fetal tissues came from previous papers whose references are given in the parentheses: the values indicated represent the extreme limits of eight individual determinations.

Table 2. Phosphofructokinase and pyruvate kinase isozyme composition of child neuroblastomas

\begin{tabular}{|c|c|c|c|c|c|c|c|c|c|c|c|c|c|}
\hline & \multicolumn{3}{|c|}{$\begin{array}{c}\text { Phosphofructokinase } \\
\% \text { of residual activity after } \\
\text { neutralization by excess }\end{array}$} & \multicolumn{10}{|c|}{ Pyruvate kinase isozymes } \\
\hline & anti $\mathbf{M}$ & anti $\mathbf{L}$ & anti $\mathrm{F}$ & I & 2 & 3 & 4 & 5 & 6 & 7 & 8 & 9 & 10 \\
\hline Adult brain $(13,17)$ & $30-40$ & $90-100$ & $25-35$ & +++ & ++ & + & & & & & & & \\
\hline Fetal brain $(10,17)$ & $20-28$ & $25-50$ & $59-80$ & ++ & + & + & ++ & & ++ & $+t$ & ++ & + & \\
\hline Neuroblastoma & 51 & 40 & 13 & + & ++ & + & ++ & + & ++ & + & +++ & + & \\
\hline Neuroblastoma & 60 & 38 & 18 & ++ & + & + & ++ & + & ++ & + & +++ & + & \\
\hline Neuroblastoma & 44 & 52 & 24 & ++ & + & + & ++ & + & ++ & + & +++ & + & \\
\hline Neuroblastoma & 40 & 27 & 20 & +++ & + & + & ++ & + & + & + & + & & \\
\hline Neuroblastoma & 33 & 27 & 15 & +++ & + & + & ++ & & & & & & \\
\hline Ganglioneuroblastoma & 30 & 45 & 32 & +++ & + & + & ++ & & & & & & \\
\hline Ganglioneuroblastoma & 39 & 42 & 16 & +++ & + & + & + & & & & & & \\
\hline Ganglioneuroblastoma & 34 & 62 & 25 & +++ & + & + & ++ & + & + & & & & \\
\hline Ganglioneuroblastoma & 27 & 46 & 10 & +++ & + & + & $+t$ & & & & & & \\
\hline Ganglioneuroblastoma & 20 & 73 & 15 & +++ & + & + & + & & & & & & \\
\hline Ganglioneuroblastoma & 21 & 75 & 10 & $++t$ & + & & + & & & & & & \\
\hline Ganglioneuroma & 34 & 70 & 10 & +++ & + & + & ++ & & & & & & \\
\hline Ganglioneuroma & 35 & 70 & 12 & $++t$ & + & & & & & & & & \\
\hline
\end{tabular}


Table 3. Phosphofructokinase and pyruvate kinase isozyme composition of various types of child malignant tumors.

\begin{tabular}{|c|c|c|c|c|c|c|c|c|c|c|c|c|c|}
\hline & \multicolumn{3}{|c|}{$\begin{array}{l}\text { Phosphofructokinase } \\
\% \text { of residual activity after } \\
\text { neutralization by excess }\end{array}$} & \multicolumn{10}{|c|}{ Pyruvate kinase isozymes } \\
\hline & anti $\mathbf{M}$ & anti $\mathbf{L}$ & anti $F$ & 1 & 2 & 3 & 4 & 5 & 6 & 7 & 8 & 9 & 10 \\
\hline Adult test & $34-40$ & $15-30$ & $80-90$ & & & & + & + & ++ & + & ++ & & \\
\hline Seminoma $(n=6)$ & $58 \pm 10$ & $22 \pm 5$ & $55 \pm 5$ & & & & & & & ++ & +++ & + & + \\
\hline $\begin{array}{l}\text { Indifferentiated teratoma } \\
\quad(n=4)\end{array}$ & $44 \pm 7$ & $23 \pm 4$ & $41 \pm 5$ & & & & & & ++ & + & +++ & + & + \\
\hline $\begin{array}{l}\text { Teratoma with nervous } \\
\text { differentiation }\end{array}$ & 24 & 30 & 60 & +++ & + & + & ++ & + & + & ++ & +++ & ++ & + \\
\hline $\begin{array}{l}\text { Indifferentiated embryonic } \\
\text { sarcoma }(n=5)\end{array}$ & $43 \pm 9$ & $29 \pm 8$ & $49 \pm 4$ & & & & & & & + & +++ & ++ & + \\
\hline Adult muscle & $0-10$ & 100 & 100 & +++ & + & & & & & & & & \\
\hline Fetal muscle & $5-25$ & $75-95$ & $80-100$ & +++ & ++ & + & ++ & + & + & & + & & \\
\hline $\begin{array}{l}\text { Poorly differentiated rhab- } \\
\text { domyosarcoma }\end{array}$ & 38 & 40 & 15 & & & & & & ++ & + & +++ & ++ & + \\
\hline Rhabdomyosarcoma & 34 & 74 & 60 & +++ & + & + & ++ & + & + & + & +++ & & \\
\hline Rhabdomyosarcoma & 40 & 20 & 58 & ++ & + & + & + & + & + & + & +++ & ++ & + \\
\hline Ewing's tumor & 50 & 40 & 26 & +++ & + & + & ++ & + & + & + & +++ & + & \\
\hline
\end{tabular}

\section{DISCUSSION}

Modification of isozymic patterns in cancer has been studied for several years. In general, the main characteristic is the reappearance or increase of synthesized forms in the fetus and in nondifferentiated cells $(9,22)$, e.g., pyruvate kinase $\mathrm{K}(1,5,24)$, aldolases $A(23)$ and non-L phosphofructokinase $(4,14,16)$ in hepatomas. It is obvious that all malignant cells are not similar and, for a given cell type, correspond to different degrees of differentiation. The question is whether some isozymes can also be used as indicators of cell type and of the stage of differentiation of the tumors. Van Veelen et al. (26) and Tolle et al. (25) have shown that this was true for pyruvate kinase in human and rodent brain tumors. It is also known that some differentiated rat hepatomas synthesized L-type pyruvate kinase, L-type phosphofructokinase and aldolase B as do normal adult hepatocytes $(3,20)$.

The main implications of the results reported in this paper are:

(1) That isozymic expression of childhood tumoral cells is roughly intermediate between that of the corresponding adult and fetal tissues but often includes some unique features not found in either adult or fetal tissues.

(2) That phosphofructokinase and pyruvate kinase are good markers for certain types of cell differentiation, namely nervous tissue and skeletal muscle differentiation. Fetal and adult kidney tissue exhibit similar pyruvate kinase and phosphofructokinase patterns; as expected, this pattern is not profoundly modified in nephroblastomas. In three cases, however, synthesis of M-type phosphofructokinase as the major form could indicate some degree of muscular differentiation, which in one case was histologically documented. All the neuroblastomas studied had common features with both adult and fetal brain: in adult brain, F-type phosphofructokinase is always the major subunit; in fetal brain, some L-type phosphofructokinase is synthesized, and both $\mathrm{K}$ and $M$ pyruvate kinase forms are expressed. Moreover, isozymic composition closely reflects level of differentiation: immature tumorous cells synthesize more L-type phosphofructokinase and $\mathrm{K}$ pyruvate kinase forms (similar to fetal brain) than more mature tumorous cells. None of the brain tumors studied exactly resembled normal fetal or adult brain pyruvate kinase and phosphofructokinase isozyme patterns. Those tumors with $\mathrm{K}-\mathrm{M}$ pyruvate kinase hybrid expression, i.e., resembling fetal brain for this marker, synthesize far more F-type and less M-type phosphofructokinase than fetal brain. Such a dissociation between these two systems of isozymic markers indicates that tumorous nervous cells should be considered as cells having a unique type of differentiation rather than as de-differentiated or undifferentiated cells.

(3) Seminomas, undifferentiated teratomas and embryonic sar- comas have the characteristics of "fetal undifferentiated cells" (10), namely expression of the most anodic pyruvate kinase forms and indiscriminate synthesis of all three phosphofructokinase subunits. As indicated above, skeletal muscle and nervous tissue differentiations are easily recognized. For instance, a teratoma containing nervous structures and synthesizing large amounts of cathodic pyruvate kinase forms and muscle-type phosphofructokinase, displayed the same phenomenon as were observed for two relatively differentiated rhabdomyosarcomas.

(4) Finally, in one case, the pyruvate kinase isozymic pattern was totally unexpected. An Ewing's tumor, normally considered as of histiocytic origin, exhibited cathodic type pyruvate kinase. The presence of $\mathrm{K}-\mathrm{M}$ pyruvate kinase hybrids and the phosphofructokinase isozymic pattern meant that these results could not be due to the presence of skeletal muscle in the biopsy sample. Inasmuch as only one sample of this type of tumor has been studied, it is impossible to discuss the significance of these findings.

In conclusion, comparison of phosphofructokinase and pyruvate kinase isozymic patterns of different types of childhood tumors confirms the general phenomenon of malignancy-linked de-differentiation, constitutes an accurate indication of skeletal muscle and nervous tissue differentiation, and sometimes reflects some unique characteristics of tumor cells.

\section{REFERENCES AND NOTES}

1. Balinsky, D., Cayanis, E., Geddes, E. W., and Bersohn, I.: Activities and isozyme patterns of some enzymes of glucose metabolism in human primary malignant hepatoma. Cancer Res., 33: 249 (1973).

2. Cottreau, D., Levin, M. J. and Kahn, A.: Purification and partial characterization of different forms of phosphofructokinase in man. Biochim. Biophys. Acta, 68 : 183 (1979)

3. Deschatrette, J. and Weiss, M. C.: Characterization of differentiated or dedifferentiated clones of a rat hepatoma. Biochimie, 56: 1603 (1974).

4. Dunaway, G. A., Morris, H. P., and Weber, G.: A comparative study of rat liver, muscle and hepatoma phosphofructokinase isozymes. Cancer Res., 34: 2209 (1974).

5. Farina, F. A., Shatton, G. B., Morris, H. P., and Weinhouse, S.: Isozymes of pyruvate kinase in liver and hepatomas of the rat. Cancer Res., 34: 1439 (1973).

6. Harada, K., Saheki, S., Wada, L., and Tanaka, T.: Purification of four pyruvate isozymes of rats by affinity elution chromatography. Biochim. Biophys. Acta. 524: 327 (1978)

7. Harkins, R. N., Black, J. A., and Rittenberg, M. B.: $\mathbf{M}_{2}$ isozyme of pyruvate kinase from human kidney as the product of a separate gene: its purification and characterization. Biochemistry, 16: 3831 (1977).

8. Ibsen, K. H.: Interrelationship and function of the pyruvate kinase isozymes and their variants: a review. Cancer Res., 37: 341 (1977).

9. Ibsen, K. H. and Fishman, W. H.: Developmental gene expression in cancer. Biochim. Biophys. Acta, 560: 243 (1979).

10. Kahn, A., Cottreau, D., and Dreyfus, J. C.: Phosphofructokinase in human fetus Pediatr. Res., 14: 1162 (1980) 
11. Kahn, A., Cottreau, D., and Meienhofer, M. C.: Purification of $F_{4}$ phosphofructokinase from human platelets and comparison with the other phosphofructokinase forms. Biochim. Biophys. Acta, 611: 114 (1980).

12. Kahn, A., Marie, J., Garreau, H., and Sprengers, E. D.: The genetic system of Ltype pyruvate kinase forms in man. Subunit structure, interrelation and kinetic characteristics of the pyruvate kinase enzymes from erythrocytes. Biochim. Biophys. Acta, 523: 59 (1978).

13. Kahn, A., Meienhofer, M. C., Cottreau, D., Lagrange, J. C., and Dreyfus, J. C.: Phosphofructokinase isozymes in man. Study of adult human tissues. Hum. Genet., 50: 1 (1979).

14. Kirby, W., Morris, H. P., and Taylor, C. B.: A comparison of the phosphofructokinase isoenzyme profiles on translatable hepatomas and normal liver. Europ. J. Cancer, 10: 629 (1974).

15. Koster, J. F., Slee, R. G., and Van Berkel, T. J. C.: Isoenzymes of human phosphofructokinase. Clin. Chim. Acta, 103: 169 (1980).

16. Kurata, N., Matsushima, T., and Sugimura, T.: Multiple forms of phosphofructokinase in rat tissues and rat tumors. Biochim. Biophys. Res. Commun., 48: 473 (1972).

17. Marie, J., Kahn, A., and Boivin, P.: Pyruvate kinase isozymes in man. I. M-type isozymes in adult and fetal tissues, electrofocusing and immunological studies. Hum. Genet., 31: 35 (1976).

18. Marie, J., Simon, M. P., Dreyfus, J. C., and Kahn, A.: One gene, but two messengers RNAs, encodes liver $L$ and red cell $L^{\prime}$ pyruvate kinase subunits. Nature, 292: 70 (1981).

19. Meienhofer, M. C., Logrand, J. C., Cottreau, D., Lenoir, G., Dreyfus, J. C., and Kahn, A.: Phosphofructokinase in human blood cells. Blood, 54: 389 (1979).

20. Reuber, M.D.: A translatable, bile-secreting hepatocellular carcinoma in the rat.
J. Nat. Cancer. Inst., 26: 891 (1961).

21. Saheki, S., Saheki, K., and Tanaka, T.: Peptide mapping by limited proteolysis of four pyruvate kinase isozymes. FEBS-Lett.. 93: 25 (1978).

22. Schapira, F.: Isozymes and cancer. Adv. Cancer. Res., 18: 77 (1973).

23. Schapira, F., Dreyfus, J. C., and Schapira, G.: Anomaly of aldolase in primary liver cancer. Nature, 200: 995 (1963).

24. Schapira, F. and Gregori, C.: Pyruvate kinase de l'hépatome, du placenta et du foie foetal de rat. C.R. Acad. Sc. Paris, 272: 1169 (1971)

25. Tolle, S. W., Dyson, R. D., Newburgh, R. W., and Cardenas, J. M.: Pyruvate kinase isozymes in neurons, glia, neuroblastomas and glioblastoma. J. Neurochem., 27: 1355 (1976).

26. Van Veelen, C. W. M., Verbiest, H., Vlug, A. M. C., Rijksen. (;., and Staal, (;. E. J.: Cancer Res., 38: 4681 (1978).

27. Vora, S., Seaman, C., Durham, S., and Piomelli, S.: Isozymes of human phosphofructokinase. Identification and subunit structural characterization of a new system. Proc. Natl. Acad. Sci., U.S.A., 77: 62 (1980).

28. Informed consent was obtained from the parents before any surgical operation or biopsy was performed in the children.

29. The authors thank the surgical department of Prof. D. Pellerin for providing the tumors and Miss B. Buisson for typing the manuscript.

30. Requests for reprints should be addressed to: Dr. Axel Kahn. INSERM U 129. Institute de Pathologie Moléculaire, CHU Cochin, 75674 Paris Cedex 14, France.

31. This research was supported by a grant from INSERM (CRL 79-5-054-2A).

32. Received for publication April 14, 1981 .

33. Accepted for publication October 6, 1981 . 